\title{
Delayed Neurologic Syndrome Associated with Carbon Monoxide Poisoning
}

\author{
Karbonmonoksit Zehirlenmesine Bağlı Geç Nörolojik Sendrom
}

\author{
(D) Erman Altunışık1, (1) Ali Zeynel Abidin Tak¹, (1) Ali Haydar Baykan² \\ ${ }^{1}$ Adiyaman University Education and Research Hospital, Clinic of Neurology, Adiyaman, Turkey \\ 2Adiyaman University Education and Research Hospital, Clinic of Radiology, Adiyaman, Turkey
}

Keywords: Carbon monoxide, intoxication, delayed neurological syndrome, magnetic resonance imaging

Anahtar Kelimeler: Karbon monoksit, intoksikasyon, geç nörolojik sendrom, manyetik rezonans görüntüleme

\section{Dear Editor,}

An 80-year-old male patient was brought to the emergency room after being found unconscious in his house, which was heated with a coal stove. He was disoriented, and his cooperation was significantly restricted. Routine blood tests, cranial computed tomography and magnetic resonance imaging (MRI) studies were unremarkable (Figure 1a, 2a). The carboxyhemoglobin level in arterial blood gas was $45.1 \%$. The patient was interned considering carbon monoxide (CO) intoxication and hyperbaric oxygen therapy was given. He was discharged with full resolution of his neurologic findings after 7 days of hyperbaric oxygen treatment. Twenty days after discharge, he was re-admitted to the emergency room with unconsciousness. His general status was poor with mental confusion. The patient was admitted to the neurology unit with suspicion of delayed encephalopathy due to CO intoxication. In T2 flair sequences in cranial MRI, symmetrical, diffuse T2-weighted high signal areas due to demyelination were observed bilaterally, affecting all cerebral deep white matter (Figures 1b, 2b).

$\mathrm{CO}$ is a non-irritant, colorless, and odorless gas formed after incomplete combustion of carbon, and has a specific gravity lower than that of the air (1). Rarely, patients may develop delayed neurologic and/or psychiatric symptoms following an initial short-term improvement after the acute treatment of $\mathrm{CO}$ intoxication, and this condition, referred to as "Delayed
Neurological syndrome (DNS)", is associated with typical cranial MRI findings such as hyperintense lesions in the subcortical white matter and basal ganglia (2). In the central nervous system, histopathologic findings associated with $\mathrm{CO}$ poisoning generally involve areas of necrosis and demyelination, particularly in the globus pallidus, deep white matter, cerebral cortex, and hippocampus (3). Our patient had no MRI findings suggestive of $\mathrm{CO}$ intoxication during the acute period. In DNS, neurologic and radiologic manifestations generally emerge within 1 to 4 weeks after the acute $\mathrm{CO}$ intoxication (3). It has been reported that the most frequent MRI finding in DNS generally includes increased T2 signal intensity, which is symmetrical in the majority of cases (4). Our patient had extensive hyperintense lesions bilaterally in the periventricular deep white matter in T2 flair sequences, consistent with demyelination. Presence of hyperintense lesions in T2 sequences is an indication of irreversible demyelination and poor prognosis (3). Our patient had quite extensive white matter involvement, and co-existence of severe encephalopathy is also supportive of poor prognosis and irreversibility, as also suggested by the absence of any clinical improvement at 12 months.

$\mathrm{CO}$ intoxication is a common condition both in our country and worldwide. It should be borne in mind that DNS can also be seen in patients who receive effective treatment. It should be noted that cranial MRI plays an important role in the diagnosis of this syndrome. 

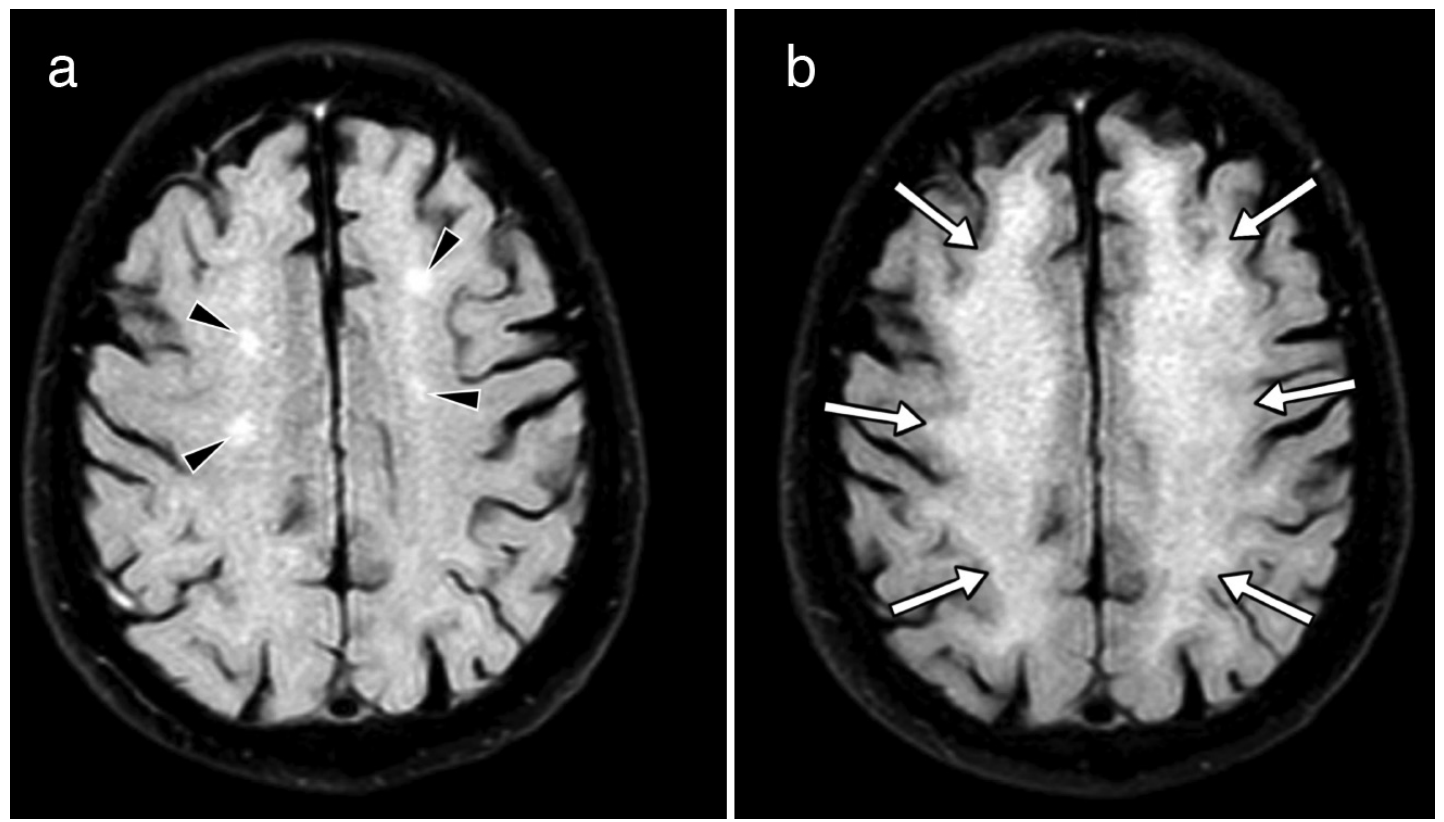

Figure 1. Axial T2 flair MRI. First (a) and follow up (b) images: Focuses (arrow heads) of chronic ischemic changes are observed in the high frontal. In the follow-up image, diffuse, bilateral deep white matter demyelinization involvement is observed (arrows)

MRI: Magnetic resonance imaging
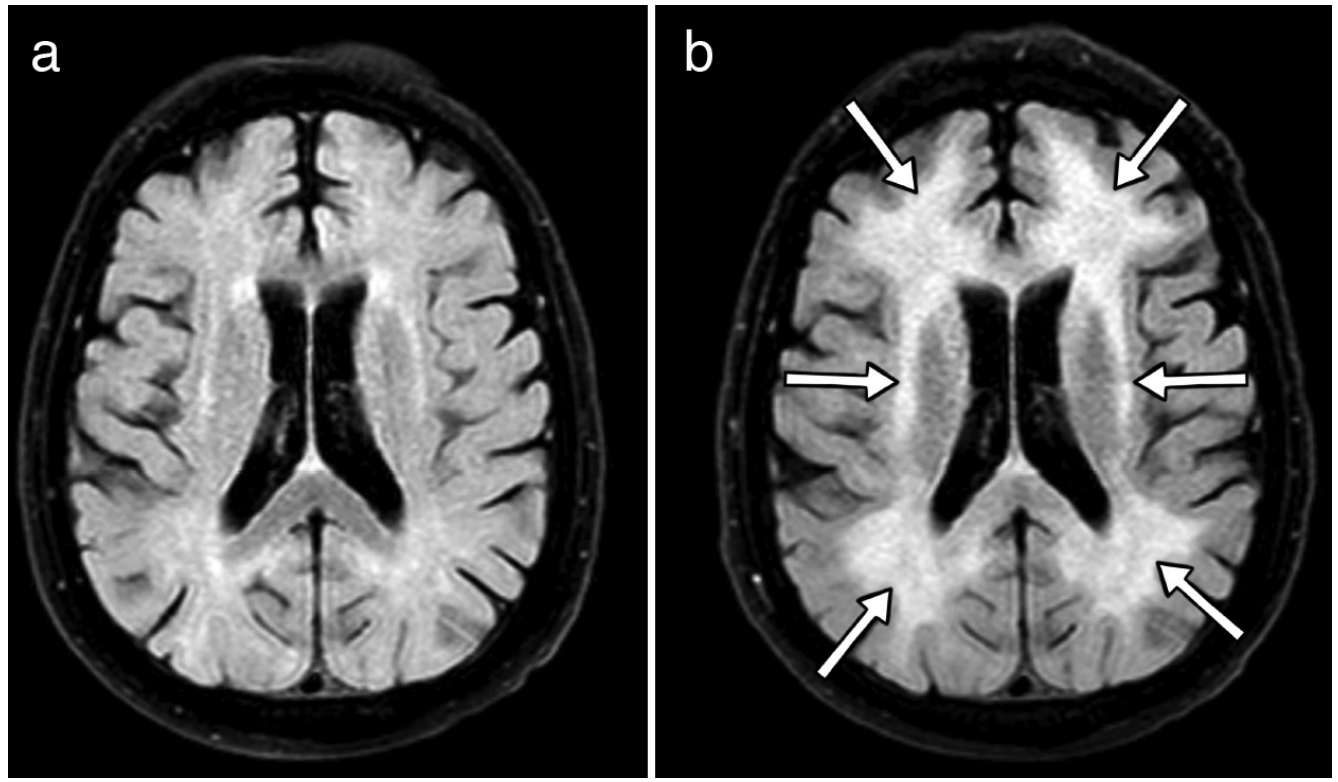

Figure 2. Axial T2 flair MRI. First (a) and follow up (b) images: Symmetrical, diffuse T2 weight high signal areas are observed bilaterally, affecting all cerebral deep white matter. Significant signal change was not observed in the first examination of the case. Cerebellum (not included in the image) and deep gray matter are preserved

MRI: Magnetic resonance imaging

Ethics

Informed Consent: Informed consent was obtained from the patient.

Peer-review: Externally peer-reviewed.

Authorship Contributions

Surgical and Medical Practices: E.A., Concept: E.A., Design:
E.A., Data Collection or Processing: A.Z.A.K., Analysis or Interpretation: A.H.B., Literature Search: A.Z.A.K., Writing: E.A.

Conflict of Interest: No conflict of interest was declared by the authors.

Financial Disclosure: The authors declared that this study received no financial support. 


\section{References}

1. Şenoğlu N, Öksüz H, Zencirci B, Ezberci M, Tuncer D. Parkinsonism after carbonmonoxide intoxication: Case Report. J Neurol Sci 2005;22:41;292296.

2. Gürlek Yüksel E, Taşkın O, Yılmaz Ovalı G, Karaçam M, Esen Danacı A. Olgu sunumu: karbonmonoksit zehirlenmesi sonrasında ortaya çıkan kleptomani ve diğer psikiyatrik belirtiler. Türk Psikiyatri Dergisi 2007:18:80-86.
3. Chang KH, Han MH, Kim HS, Wie BA, Han MC. Delayed encephalopathy after acute carbonmonoxide intoxication: MR imaging features and distribution of cerebral white matter lesions. Radiology 1992;184:117-122.

4. Uchino A, Hasuo K, Shida K, et al. MRI of thebrain in chronic carbonmonoxide poisoning. Neuroradiology 1994;36:399-401. 